\title{
1 Implication of nitrate in drinking water in Kawauchi village,
}

\section{Fukushima}

4 Makiko Orita $^{1}$, Keita Iyama ${ }^{2}$, Naomi Hayashida ${ }^{3}$, Norisato Mitsutake ${ }^{2}$, Shinichi Suzuki ${ }^{4}$,

$5 \quad$ Shunichi Yamashita ${ }^{2}$, Noboru Takamura ${ }^{1}$

6

$7 \quad{ }^{1}$ Department of Global Health, Medicine, and Welfare, and ${ }^{2}$ Department of Disaster

8 Medicine and ${ }^{3}$ Division of Strategic Collaborative Research, Center for Promotion of

9 Collaborative Research on Radiation and Environment Health Effects, Atomic Bomb

10 Disease Institute, Nagasaki University Graduate School of Biomedical Sciences,

11 Nagasaki, Japan

$12{ }^{4}$ Department of Thyroid and Endocrinology, Fukushima Medical University School of 13 Medicine, Fukushima, Japan

$15{ }^{*}$ Address corresponding to: Noboru Takamura, M.D., Ph.D.

16 Professor, Department of Global Health, Medicine and Welfare, Atomic Bomb Disease

17 Institute, Nagasaki University Graduate School of Biomedical Sciences

18 1-12-4 Sakamoto, Nagasaki 852-8523, Japan 
$1 \quad$ E-mail: takamura@nagasaki-u.ac.jp

2

3 Dear Editor:

4 Four years has passed since the accident at Fukushima Daiichi nuclear power plant

5 (FDNPP). The thyroid ultrasound examination within the framework of the Fukushima

6 Health Survey being conducted in Fukushima Prefecture has targeted all prefectural

7 inhabitants who were less than 18 years of age at the accident (approximately 360,000

8 inhabitants). The first cycle of screening, which took place between October 2011 and

9 March 2014, showed that amongst 297,046 screened individuals, 112 had confirmed or

10 suspected malignancies. Nevertheless, the causal relationship between radiation

11 exposure and thyroid cancer in this cycle should be carefully evaluated since the

12 radiation dose to the thyroid gland in Fukushima was quite low when compared to that

13 in Chernobyl (the maximum thyroid radiation dose in Fukushima was $35 \mathrm{mSv}$, whereas

14 the mean dose in Chernobyl was $240 \mathrm{mSv})(1,2)$, and the ages of children with thyroid

15 cancer were less than 10 years old at the time of the accident in Chernobyl, whereas in

16 Fukushima, so far, no children were less than 5 years and only a few cases were less

17 than 10 years old at the time of the accident (1).

18 Besides ionizing radiation exposure, nitrate is considered as a risk factor for thyroid 
1 cancers. Nitrate and nitrite are precursors in the endogenous formation of N-nitroso

2 compounds, which are potent animal carcinogens that cause thyroid and many other

3 tumors in animal models (3). An epidemiological study in older women in Iowa showed

4 an increased risk of thyroid cancer with higher average nitrate levels in public water

5 supplies and with longer consumption of water exceeding $5 \mathrm{mg} / \mathrm{L}$ nitrate- $\mathrm{N}$ (3). The

6 possibility of a similar relationship between the incidence of thyroid cancer in

7 Fukushima and consumption of nitrate-containing water has not been evaluated. In this

8 report, we conducted a preliminary evaluation of nitrate concentrations in drinking

9 water in Kawauchi village, Fukushima Prefecture, located within 30km of the FDNPP.

10 We investigated nitrate nitrogen concentrations in the drinking water of Kawauchi

11 village (Total population; 2,700 and total households; 1,100) (4), where all inhabitants

12 use their own private wells as the main source of drinking water. We collected water

13 from 104 household wells in the village (Figure 1) and analyzed the nitrate/nitrite

14 nitrogen concentrations by the naphthylethylene-diamine method (Pack Test, Kyoritsu

15 Chemical-Check Lab., Corp, Tokyo, Japan). The median $\left(25^{\text {th }}-75^{\text {th }}\right)$ nitrate nitrogen

16 level was $0.62 \mathrm{mg} / \mathrm{L}(0.20-2.51 \mathrm{mg} / \mathrm{L})$, which did not exceed the recommended

17 maximum contamination levels (MCL) of $10 \mathrm{mg} / \mathrm{L}$ for nitrate nitrogen in water samples

18 in Japan. The nitrite nitrogen concentrations in any well also did not also exceed 
$10.005 \mathrm{mg} / \mathrm{L}$, the recommended MCL in Japan. Our preliminary results suggested that

2 nitrate in drinking water does not contribute significantly to thyroid disorders in

3 Kawauchi village of Fukushima. In Fukushima Prefecture, many inhabitants usually use

4 tap water. Since tap water is more regulated than private wells, nitrate nitrogen exposure

5 from drinking water is considered to be limited in inhabitants of Fukushima.

6 In addition to investigations including the evaluation of dietary nitrate intake, further

7 epidemiological studies are needed to clarify the factors contributing to the incidence of

8 thyroid diseases, including malignancies, in Fukushima.

9

10 Acknowledgements

11 This publication was supported by research grant (No. 26670460) from Japan Society

12 for the Promotion of Science (JSPS).

14 Author Disclosure Statement

15 No competing financial interests exist.

\section{References}

18 1. Nagataki S, Takamura N 2014 A review of the Fukushima Nuclear Reactor 
1 Accident: Radiation effects on the thyroid and strategies for prevention. Curr Opin

$2 \quad$ Endocrinol Diabetes Obes 21: 384-393.

3 2. Cardis E, Kesminiene A, Ivanov V, Malakhova I, Shibata Y, Khrouch V,

4 Drozdovitch V, aceika E, Zvonova I, Vlassov O, Bouville A, Goulko G, Hoshi M,

5 Abrosimov A, Anoshko J, Astakhova L, Chekin S, Demidchik E, Galanti R, Ito M,

6 Korobova E, Lushnikov E, Maksioutov M, Masyakin V, Nerovnia A, Parshin V,

7 Parshkov E, Piliptsevich N, Pinchera A, Polyakov S, Shabeka N, Suonio E, Tenet V,

8 Tsyb A, Yamashita S, Williams D 2005 Risk of thyroid cancer after exposure to

$9 \quad$ 131I in childhood. J Natl Cancer Inst 97: 724-732.

3. Ward MH, Kilfoy BA, Weyer PJ, Anderson KE, Folsom AR, Cerhan JR 2010 Nitrate intake and the risk of thyroid cancer and thyroid disease. Epidemiology 21: 389-395.

4. Orita M, Hayashida N, Urata H, Shinkawa T, Endo Y, Takamura N 2013 Determinants of the return to hometowns after the accident at Fukushima Dai-ichi nuclear power plant: a case study for the village of Kawauchi. Radiat Prot Dosimetry 156: 383-385. 


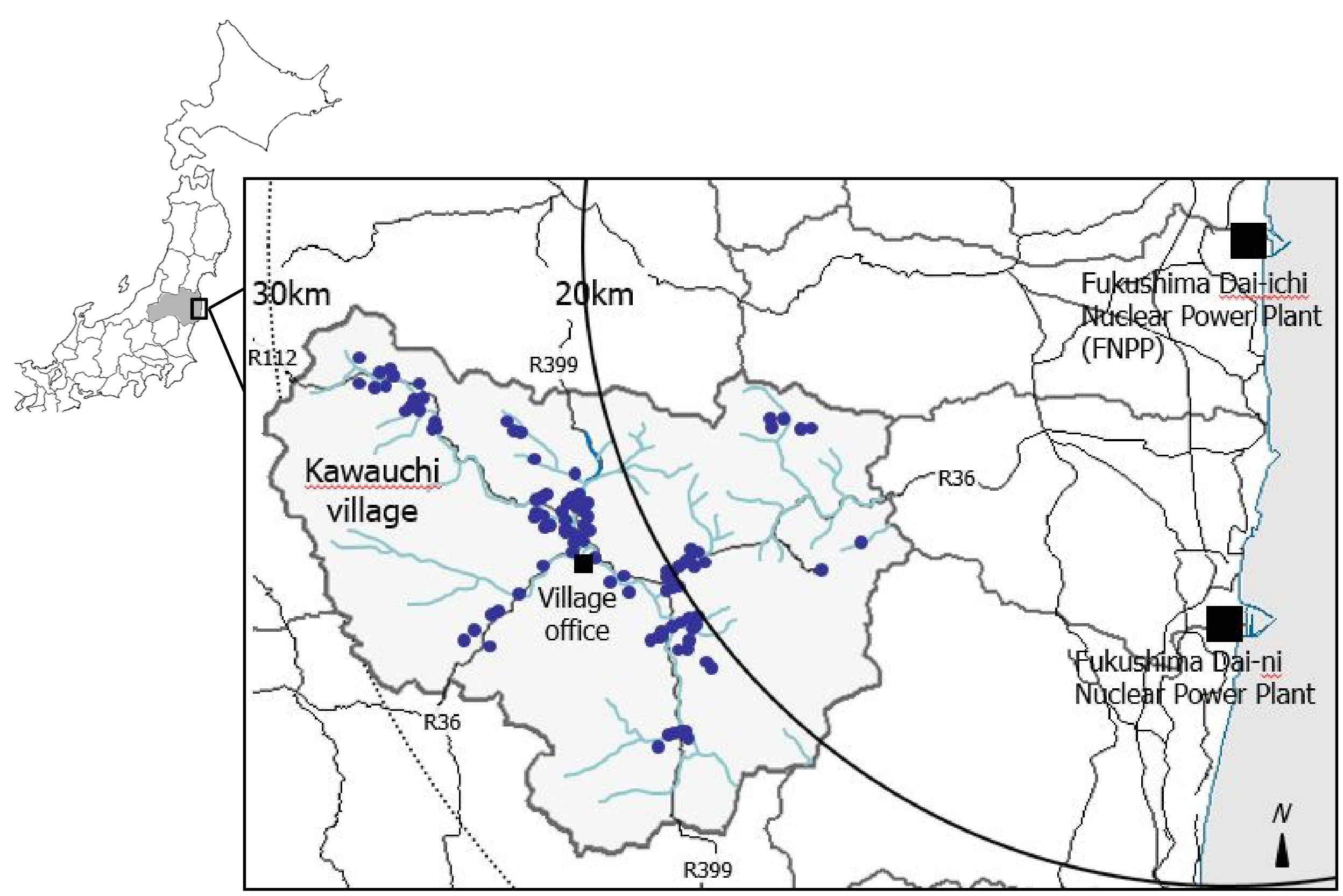

FIG. 1.

Sampling points of water for the measurement of nitrate/nitrite nitrogen concentrations in Kawauchi village. 